\title{
120 \\ Present status of mangroves in three different water bodies associated sites in Thirukkovil and Pottuvil, Ampara district
}

\author{
$P$ Manoharan and T Shripathy \\ Faculty of Science, Eastern University, Sri Lanka
}

Thirukkovil and Pottuvil villages in Ampara district are well known for Ecotourism. Village ecotourism is based on the beauty of the coastal belt and its surrounds which is decorated by flora and fauna within its geographical sites. A predominant flora of the coastal villages, along the water bodies are mangroves and this was either fully or partially devastated by tsunami tidal waves in 2004 . Studing the present status of mangroves is important for the ecotourism since it enables the present plant forms and by replanting the appropriate species. The aim of the study was to evaluated the present status of mangroves, in the three selected water bodies associate sites namely Maranakandy River in Thirukkovil, Kudakali Lagoon \& Dhua Lagoon in Pottuvil, Ampara district, which was carried out in July 2006.

An impact of tidal waves on mangroves and its associates was not clearly evident in Maranakandy River, where an impact was clearly seen in Kudakali lagoon, but least was noted in Dhua lagoon, at the time of study. This impact difference possibly by the distances of sea point's from the sites and the types of mangrove vegetation the sites liad at that time. Maranakandy River was under continuous exploitation by local communities compared to Kudakali lagoon and Dhua lagoon, which located next to each other, but at a distance and an undisturbed state. Both true and associated mangroves species were naturally segregated in all three sites. Predominant species was Rhizophora sp, except in Dhua lagoon. In Dhua lagoon, along the sites, but opposite to the sea, root stumps and prop roots were left out as evident destructive parts of Rhizophora sp. by tidal waves impact and no species were seen in the premises. Rhizophora sp. was grown adjacent and along the sites in Maranakandy River and Kudakali lagoon, where Excoecaria agallocha and Bruguiera gymmorhiza were at its immediate right backyard, respectively. $R$. mucronata showed a stunted growth in Maranakandy River, where as $R$. apiculata recorded in Kudakali lagoon was overgrown to a height of $6 \mathrm{~m}$. As such, a morphological habit of $R$. apiculata possibly served as a colliding object for the impact of tidal waves in Kudakali lagoon and thus impact of tidal waves was greater on $R$. apiculata, mainly at the entry point of sea water. Tall grown B. gymnorhiza_was only recorded in Kudakali lagoon and impact of tidal waves were negligible, since $R$. apiculata was in the frontier line and sacrificed first while safe guarded the $B$. gymnorhiza. Natural regenerations by numerous $B$. gymnorhiza seedlings were seen and being occupied in the devastated sites of $R$. apiculata in Kudakali lagoon. Replantation of R. mucronata seedlings were noted in Maranakandy River, except in Dhua lagoon. Thus, on site basis, a planned replantation of mangroves is necessary to uplift the socio-economic life of three sites in the district. perhaps ecotourism. 